\title{
RESEARCH
}

Open Access

\section{Effect of discontinuation of ticagrelor and switching-over to other P2Y12 agents in patients with acute coronary syndrome: a single-center real-world experience from India}

Nagendra Boopathy Senguttuvan ${ }^{1,2,3^{*}}$, Ramesh Sankaran¹, Yashasvi Rajeev ${ }^{4}$, Devi Thaiyal ${ }^{3}$, Angel Mathew ${ }^{3}$, K. Dharsini ${ }^{3}$, Divya Marcelene ${ }^{3}$, Maria Jusler Kalsingh ${ }^{5}$, Sujit Kumar Sahu ${ }^{3}$, Aravind Sampath ${ }^{3}$, K. J. Prem Kumar ${ }^{3}$, Harikrishnan Parthasarathy ${ }^{3}$, Amal Louis ${ }^{3}$, Anand Gnanaraj ${ }^{3}$, K. N. Reddy ${ }^{3}$ and K. A. Abraham ${ }^{3}$

\begin{abstract}
Background: Dual antiplatelet therapy is the current standard of care after acute coronary syndrome (ACS) and percutaneous coronary intervention (PCI). We intended to study the pattern of use of ticagrelor in patients with acute coronary syndrome undergoing $\mathrm{PCl}$ and the effect of switching over to other P2Y12 receptor inhibition on clinical outcomes.
\end{abstract}

Results: All patients aged > 18 years who had been admitted with acute coronary syndrome and had been provided ticagrelor as the second antiplatelet agent were included as study participants. The primary outcome of the study was the composite outcome of death, recurrent myocardial infarctions, re-intervention, and major bleeding. We studied 321 patients (54 female patients, 16.82\%). The mean age of the patients was $56.65 \pm 11.01$ years. Ticagrelor was stopped in $76.7 \%$ on follow-up. It was stopped in $6.3 \%, 13.5 \%, 13.1 \%, 21.9 \%$, and $45.1 \%$ of patients during the first month but after discharge, between first and third months, between 3 and 6 months, between 6 and 12 months, and after 12 months, respectively. In the majority of patients, ticagrelor was replaced by clopidogrel (97.9\%). It was stopped according to the physician's discretion in $79.3 \%$ of patients, whereas it was the cost of the drug that made the patient to get swapped to another agent in $18.6 \%$. No difference in the primary composite outcome was observed between the groups where ticagrelor was continued post 12 months and ticagrelor was continued and ticagrelor was switched-over to another agent. Similarly, no difference in death, recurrent myocardial infarctions, reinterventions, or major bleeding manifestations was observed between the two groups.

Conclusion: In patients with acute coronary syndrome who undergo $\mathrm{PCl}$, we observed that early discontinuation of ticagrelor and switching over to other P2Y12 inhibitors after discharge did not affect clinical outcomes.

Keywords: Ticagrelor, Acute coronary syndrome, Bleeding, Clopidogrel, Switch over

\footnotetext{
* Correspondence: nagendraboopathy@sriramachandra.edu.in;

drsnboopathy@gmail.com

'Department of Cardiology, Sri Ramachandra Institute of Higher Education and Research, Chennai, Tamil Nadu, India

${ }^{2}$ Adjunct Faculty-Indian Institute of Technology Madras, Chennai, Tamil Nadu, India

Full list of author information is available at the end of the article
} 


\section{Background}

Coronary artery disease remains a major public health concern in India affecting people at their productive younger age. A recently published study from the state of Kerala estimated a prevalence of any CAD to be $12.5 \%$ (men 9.8\%, women 14.3\%) without any difference in urban and rural population [1]. Percutaneous coronary interventions (PCI) are increasingly used in our country. The role of $\mathrm{PCI}$ in patients with acute coronary syndrome especially ST-elevation MI is well established [2]. Anti-platelet drugs play a crucial role in the treatment of ACS. Dual antiplatelet therapy is the established mode of treatment in such scenarios. Until recently, it was clopidogrel that was available in treating such patients. At present, two more ADP receptor antagonists are available that include prasugrel and ticagrelor. It has been shown in TRITON TIMI-38, which was a randomized 13,608 patients with moderate-to-high-risk acute coronary syndromes with scheduled percutaneous coronary intervention to prasugrel or clopidogrel, that patients in the prasugrel arm had significantly reduced rates of ischemic events, including stent thrombosis. They also found that patients in the prasugrel arm had increased risk of major bleeding, including fatal bleeding [3]. Wallentin et al., in PLATO trial, studied 18,624 patients with acute coronary syndrome. They randomized the groups to clopidogrel or ticagrelor. They found that there was a significant reduction (absolute reduction of $1.9 \%)$ in the primary endpoint of the study that comprised of death from vascular causes, myocardial infarction, or stroke [4]. The rate of overall major bleeding was the same between the arms with an increase in the rate of non-procedure-related bleeding. Hence, it has been clearly shown in these two large randomized control trials that ticagrelor and prasugrel were superior to clopidogrel in patients with ACS [3, 4]. USFDA has approved both these agents in the treatment of patients with acute coronary syndrome who are getting intervened Though it is presumed that these drugs should act similarly in our Indian patients, there is a lack of indigenous evidence to prove the same. Similarly, the safety and efficacy of switching over from ticagrelor to clopidogrel is being addressed in many global studies. To our knowledge, no data is available from the subcontinent. Therefore, we intended to study the pattern of use of ticagrelor in patients with acute coronary syndrome undergoing PCI and the effect of switching over to other P2Y12 receptor inhibition on clinical outcomes in our study.

\section{Methods}

Our study was a non-randomized, retrospective, singlecenter, observational study. It was an investigatorinitiated, non-funded study. All patients aged $>18$ years who had been admitted with acute coronary syndrome and had been provided ticagrelor as the second antiplatelet agent in the Department of Cardiology were included as study participants. The study was approved by Institutes Ethics committee, and patients provided their informed consent for the participation in the study. Study participants were identified from medical records through copyrighted software. Those patients who fulfilled the requirements were called individually by a research coordinator for detailed clinical assessment by their respective physicians. In case they were not able to make it in person, the necessary information was obtained from them over the phone. Baseline characteristics of the included but deidentified patients like age, sex, and presence of traditional risk factors for CAD including diabetes, hypertension, and dyslipidemia were

Table 1 Baseline characteristic of patient populations.

\begin{tabular}{|c|c|c|}
\hline Characteristics & Number-321 & $N \%$ \\
\hline Age & $56.65 \pm 11.01$ years & \\
\hline Female & 54 & 16.80 \\
\hline Diabetes mellitus & 182 & 56.70 \\
\hline Insulin-dependent diabetes mellitus & 27 & 8.40 \\
\hline Hypertension & 168 & 52.30 \\
\hline Prior CAD & 141 & 43.90 \\
\hline Unstable angina & 128 & 39.90 \\
\hline NSTEMI & 41 & 12.80 \\
\hline STEMI & 152 & 47.40 \\
\hline$E F \leq 30 \%$ & 11 & 3.40 \\
\hline$E F \geq 55 \%$ & 186 & 57.90 \\
\hline EF-30-45\% & 60 & 18.70 \\
\hline EF-45-55\% & 64 & 19.90 \\
\hline Clopidogrel & 86 & 26.80 \\
\hline Prasugrel & 7 & 2.20 \\
\hline Aspirin & 113 & 35.20 \\
\hline Ticagrelor & 30 & 9.30 \\
\hline Statin & 131 & 40.80 \\
\hline Prior bleeding & 3 & 0.90 \\
\hline LAD & 177 & 55.10 \\
\hline LCX-OM & 51 & 15.90 \\
\hline RCA & 88 & 27.40 \\
\hline Left main & 5 & 1.60 \\
\hline Plain old balloon angioplasty (POBA) & 4 & 1.20 \\
\hline DES & 315 & 98.2 \\
\hline BMS & 2 & 0.60 \\
\hline YES & 266 & 82.90 \\
\hline Non-culprit vessel intervention & 81 & 25.50 \\
\hline Recurrent Ml & 4 & 1.20 \\
\hline Re-intervention & 3 & 0.90 \\
\hline
\end{tabular}




\section{A Group-1, 237 (Ticagrelor discontinued) Group-2, 72 (Ticagrelor continued)}

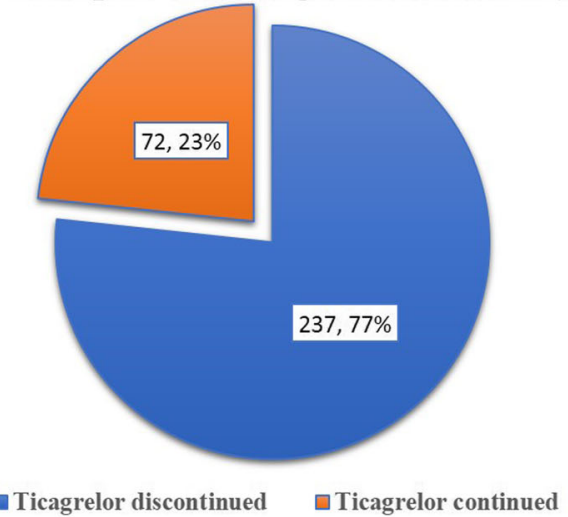

B

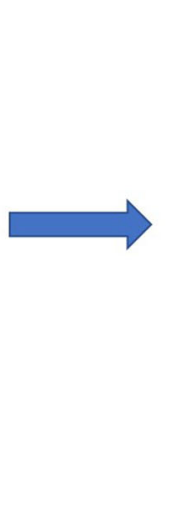

Timing of discontinuation of ticagrelor

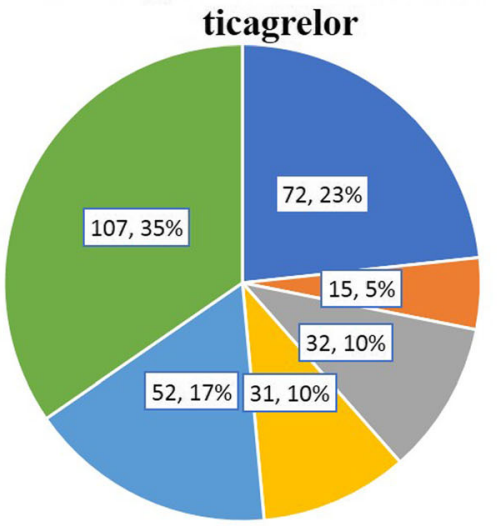

- Ticagrelor continued $\|<1$ MONTH

1-3 MONTH

3-6 MONTH

- 6-12 MONTH

- $>12$ MONTH

Fig. 1 a Percentage of patients who discontinued ticagrelor. b Timing of discontinuation of Ticagrelor.

studied. Patients were categorized into those with unstable angina, non-ST elevation myocardial infarction (NSTEMI), and ST-elevation myocardial infarction (STEMI). All available laboratory parameters were noted including electrocardiogram, transthoracic echocardiogram, angiographic findings, and interventional procedural along with clinically significant bleeding that required transfusions, reintervention, and recurrent myocardial infarction. Patients were specifically asked about their symptoms and adherence to antiplatelet agents. Details about the continuation of ticagrelor after procedure were also noted. Based on the same, they

Table 2 Clinical outcomes in ticagrelor discontinued group and ticagrelor continued group.

\begin{tabular}{|c|c|c|c|c|c|}
\hline & \multicolumn{2}{|c|}{ Group 1, n-237 } & \multicolumn{2}{|c|}{ Group 2, n-72 } & \multirow{2}{*}{$\begin{array}{l}p \\
\text { value }\end{array}$} \\
\hline & $n$ & $n \%$ & $n$ & $n \%$ & \\
\hline Female & 44 & 18.60 & 7 & 9.70 & 0.077 \\
\hline Insulin-dependent diabetes mellitus & 13 & 5.50 & 10 & 13.90 & 0.017 \\
\hline Prior bleeding & 7 & 3.00 & 5 & 6.90 & 0.125 \\
\hline Hypertension & 113 & 47.70 & 46 & 63.90 & 0.016 \\
\hline Prior CAD & 101 & 42.60 & 31 & 43.10 & 0.947 \\
\hline Unstable angina & 101 & 42.60 & 24 & 33.30 & 0.16 \\
\hline NSTEMI & 25 & 10.50 & 12 & 16.70 & \\
\hline STEMI & 111 & 46.80 & 36 & 50.00 & \\
\hline$E F \leq 30 \%$ & 7 & 3.00 & 1 & 1.40 & 0.234 \\
\hline$E F \geq 55 \%$ & 133 & 56.10 & 48 & 66.70 & \\
\hline EF-30-45\% & 44 & 18.60 & 14 & 19.40 & \\
\hline EF-45-55\% & 53 & 22.40 & 9 & 12.50 & \\
\hline Left anterior descending artery (LAD) & 126 & 53.20 & 41 & 56.90 & 0.709 \\
\hline LCX-OM & 41 & 17.30 & 10 & 13.90 & \\
\hline RCA & 67 & 28.30 & 19 & 26.40 & \\
\hline Left main & 3 & 1.30 & 2 & 2.80 & \\
\hline Recurrent Ml & 3 & 1.30 & 1 & 1.40 & 0.936 \\
\hline Re-intervention & 3 & 1.30 & 0 & 0.00 & \\
\hline
\end{tabular}


Table 3 Comparison of baseline characteristics between ticagrelor discontinued and ticagrelor continued arms.

\begin{tabular}{lllll}
\hline S. no. & Outcomes & Ticagrelor discontinued (237) & Ticagrelor continued (72) & $\boldsymbol{p}$ value \\
\hline 1 & Composite outcome(n,\%) & $11(4.6 \%)$ & $6(8.3)$ & 0.23 \\
2 & Death & 0 & 0 & $\mathrm{NA}$ \\
3 & Recurrent Ml & $3(1.3 \%)$ & $1(1.4 \%)$ & 0.94 \\
4 & Re-intervention & $3(1.2 \%)$ & 0 & 0.34 \\
5 & Major bleeding & $7(3 \%)$ & $5(6.9)$ & 0.12 \\
\hline
\end{tabular}

were divided into two groups. Group 1 where ticagrelor was discontinued and group 2 where it was continued. If it was stopped or swapped to a different p2Y12 inhibitor before one year, an attempt was made to analyze the reason for the same. The primary outcome of the study was the composite outcome of death, recurrent myocardial infarctions, re-intervention, and major bleeding requiring transfusions. We also intended to study the reason for the switch-over and its relation with clinical outcomes.

\section{Statistical analysis}

Descriptive data were expressed in terms of ratio, proportion, or percentage; mean and median (interquartile range) were used for discrete quantitative data. Continuous variables were analyzed by $t$ test. Categorical variables were analyzed by chi-squared test. A $p$ value $<0.05$ was considered significant. SPSS v20 (IBM) was used for statistical analysis.

\section{Results}

We identified 336 patients. Out of this, we studied 321 patients (54 female patients, 16.8\%) after the exclusion of 15 patients who could not be reached. The mean age of the patients was $56.65 \pm 11.01$ years (Table 1). The median duration of follow-up was 22 months (interquartile range 18). History of diabetes and hypertension were present in $56.7 \%$ and $52.3 \%$, respectively. Prior history of CAD was present in $43.9 \%$. Most of the patients had
STEMI (47.4\%) while $39.9 \%$ had unstable angina, and $12.8 \%$ had NSTEMI. The majority of the patients had good LV systolic function with an ejection fraction of > $55 \%$ in $57.9 \%$. Mild LV dysfunction (LVEF45-55\%), moderate LV dysfunction (30-45\%), and severe LV dysfunction $(<30 \%)$ were present in $19.9 \%, 18.7 \%$, and $3.4 \%$, respectively. Nearly one third of the patients (35.2\%) were taking aspirin before the index procedure. Some of the patients were receiving other antiplatelet agents that included $26.8 \%$ of patients with clopidogrel, $2.2 \%$ of patients with prasugrel, and $9.3 \%$ of patients with ticagrelor. More than $40 \%$ of individuals were using a statin. The history of prior bleeding was noted in $0.9 \%$. The majority of the patients had left anterior descending artery (LAD) territory involvement. Most patients (98.8\%) received stents, while $1.2 \%$ received plain old balloon angioplasty. Only two patients had received bare-metal stents. The mean stent used per patient was 1.3. Most of the patients had received Gp2b/3a inhibitor (82.9\%). Non-culprit vessel intervention was done in $25.5 \%$ of patients during the index procedure or the same admission.

We excluded 12 patients who died before discharge for further analysis, as all patients were on ticagrelor during that period, i.e., before discharge from index hospital admission. This resulted in 309 patient populations for further analysis. No patient died during the followup study period. They were classified into group 1 (ticagrelor discontinued) and group 2 (ticagrelor continued)

Table 4 Reason for discontinuation of ticagrelor and its timing

\begin{tabular}{|c|c|c|c|}
\hline & Characteristics & Group-1, n-237 & $\%$ \\
\hline \multirow[t]{6}{*}{ Reason for stopping ticagrelor } & Reason not known & 1 & 0.40 \\
\hline & Cost of the drug & 44 & 18.60 \\
\hline & Physician's discretion & 188 & 79.30 \\
\hline & Non-availability of the drug & 3 & 1.30 \\
\hline & Side effect & 1 & 0.40 \\
\hline & Timing of discontinuation & Group 1, n-237 & \\
\hline \multirow[t]{5}{*}{ Timing of discontinuation of ticagrelor } & $<1$ month & 15 & 6.30 \\
\hline & $1-3$ months & 32 & 13.50 \\
\hline & $3-6$ months & 31 & 13.10 \\
\hline & 6-12 months & 52 & 21.90 \\
\hline & $>12$ months & 107 & 45.10 \\
\hline
\end{tabular}


(Fig. 1 and Table 2). Ticagrelor was stopped and switched-over to other P2Y12 inhibitor in $76.7 \%$ of patients. Insulin-dependent diabetes status and hypertensive status were significantly more common in the group where ticagrelor was continued (Table 2). The primary composite event happened in $4.6 \%$ in the group where ticagrelor was discontinued and $8.3 \%$ where ticagrelor was continued ( $\mathrm{p}-0.23$, Table 3$)$. Three out of $237 \mathrm{pa}-$ tients in whom ticagrelor was stopped early had recurrent MI while 1 out of 72 patients in the other arm had recurrent MI (P-non-significant). Similarly, no difference was seen in re-interventions and major bleeding between the studied groups (Table 3). The primary composite event happened in $5.5 \%$ in the group where ticagrelor was discontinued and $8.3 \%$ where ticagrelor was continued (p-0.229, Table 3). Three out of 237 patients in whom ticagrelor was stopped early had recurrent MI, while 1 out of 72 patients in the other arm had recurrent MI (P-non-significant). Similarly, no difference was seen in re-interventions and major bleeding between the studied groups (Table 3). There was no difference in the treated culprit vessel between the groups.

In the majority of those patients, it was stopped before 6 months. Period of stopping was classified empirically into five periods (Table 4 and Fig. 1). They were before the first month but after discharge from index hospitalization, between the first and third months, between 3 and 6 months, between 6 and 12 months, and after 12 months. It was stopped in $6.3 \%, 13.5 \%, 13.1 \%$, $21.9 \%$, and $45.1 \%$ of patients during the first month, between first and third months, between 3 and 6 months, between 6 and 12 months, and after 12 months, respectively (Table 4). We classified the basis for early discontinuation into four possible causes (Table 3 and Fig. 2). They were (1) stopped due to the high cost of the drug, (2) stopped due to physician-based discretion, (3) stopped due to non-availability of drugs, and (4) stopped due to side effects. They were stopped according to physician's discretion in $79.3 \%$ of patients, whereas it was the cost of the drug that made the patient to get swapped to another agent in $18.6 \%$ (Table 4). Only in a very small number of patients, it was stopped due to non-availability or side effect. Dyspnea was the reason to stop the drug in one patient during follow-up. In the majority of patients, ticagrelor was replaced by clopidogrel $(97.9 \%)$, while in the remaining prasugrel was used. Most of the patients were loaded with a $300 \mathrm{mg}$ loading dose of clopidogrel followed by $75 \mathrm{mg}$ of maintenance dose while switchingover from ticagrelor. We assessed the effect various factors like diabetes, ACS, LV ejection fraction, reason for stopping ticagrelor, time of stopping ticagrelor, and nature of new drug added instead of ticagrelor on our primary outcome and found no significant association between any of the factors and the primary outcome (Table 5).

\section{Discussion}

In this real-world single-center experience study, we observed early discontinuation of ticagrelor after discharge, and switching-over to other P2Y12 agents in patients with acute coronary syndrome did not affect clinical outcomes. It was found that ticagrelor was stopped early, i.e., before the end of the first year in the majority of patients. It happened more frequently after 6 months post PCI. Though the cost of ticagrelor remained an

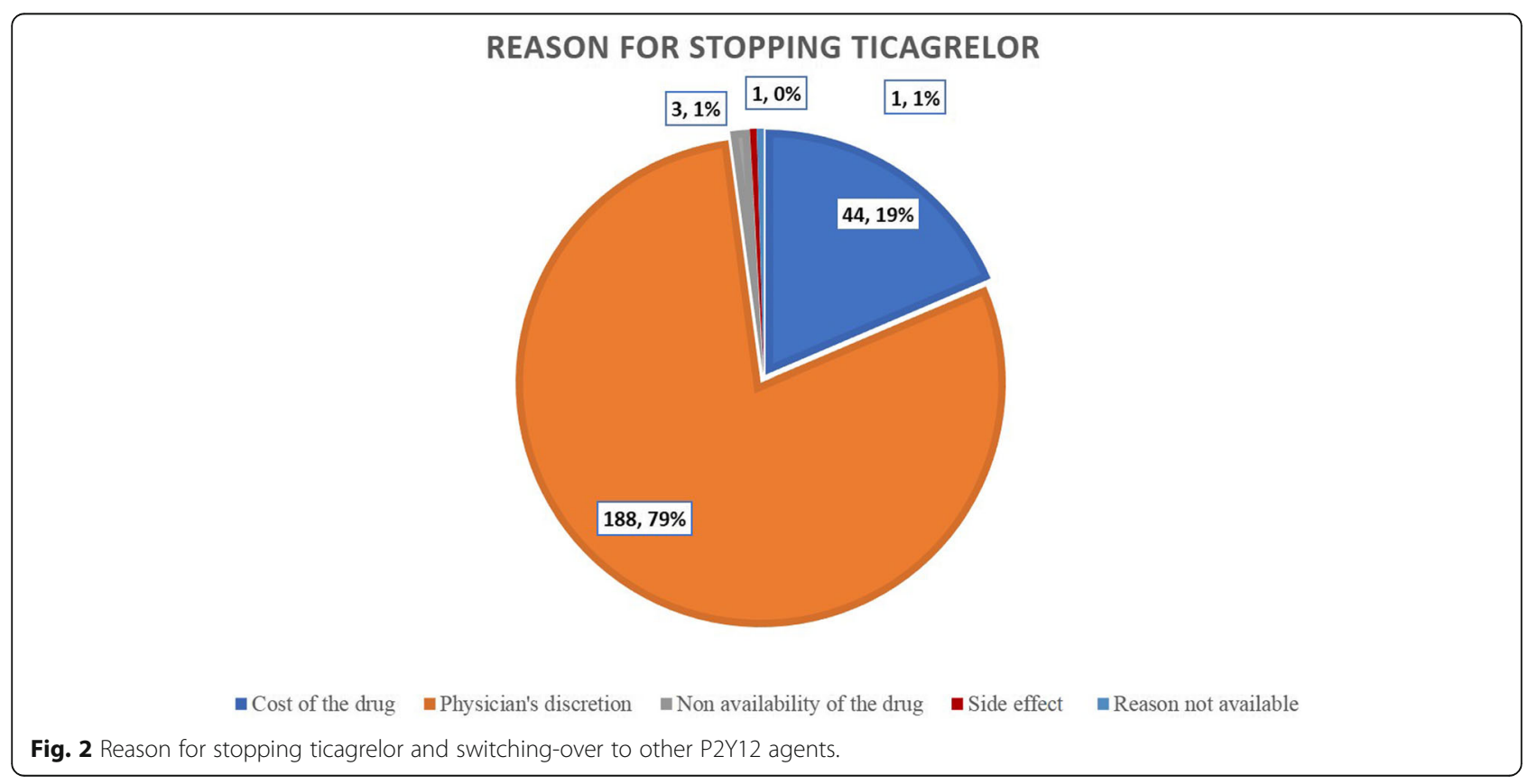


Table 5 Effect of various factors like diabetes, ACS, EF, reason for stopping ticagrelor, time of stopping ticagrelor, and nature of new drug added instead of ticagrelor on our primary outcome

\begin{tabular}{|c|c|c|c|c|c|}
\hline & \multicolumn{2}{|c|}{$\begin{array}{l}\text { Primary outcome happened, } \\
\mathrm{N}-17\end{array}$} & \multicolumn{2}{|c|}{$\begin{array}{l}\text { Primary outcome did not happen, N- } \\
292\end{array}$} & \multirow[t]{2}{*}{$\begin{array}{l}p \\
\text { value }\end{array}$} \\
\hline & $\bar{n}$ & $n \%$ & $\bar{n}$ & $n \%$ & \\
\hline Diabetes & 7 & 41.2 & 130 & 44.5 & 0.79 \\
\hline \multicolumn{6}{|l|}{ Acute coronary syndrome group } \\
\hline USA & 7 & 41.2 & 118 & 40.4 & \multirow[t]{3}{*}{0.99} \\
\hline NSTEMI & 2 & 11.8 & 35 & 12.0 & \\
\hline STEMI & 8 & 47.1 & 139 & 47.6 & \\
\hline \multicolumn{6}{|l|}{ Ejection fraction } \\
\hline$E F \leq 30 \%$ & 0 & 0.0 & 8 & 2.7 & \multirow[t]{4}{*}{0.8} \\
\hline$E F \geq 55 \%$ & 11 & 64.75 & 170 & 58.2 & \\
\hline EF-30-45\% & 3 & 17.6 & 55 & 18.8 & \\
\hline$E F-45-55 \%$ & 3 & 17.6 & 59 & 20.2 & \\
\hline \multicolumn{6}{|l|}{ Culprit vessel } \\
\hline Left anterior descending artery (LAD) & 7 & 41.2 & 160 & 54.8 & \multirow[t]{4}{*}{0.32} \\
\hline Circumflex (LCX) & 2 & 11.85 & 49 & 16.8 & \\
\hline Right coronary artery (RCA) & 8 & 47.1 & 78 & 26.7 & \\
\hline Left main or triple vessel disease & 0 & 0.0 & 5 & 1.7 & \\
\hline \multicolumn{5}{|l|}{ Reason for stopping } & \multirow[t]{6}{*}{0.70} \\
\hline Ticagrelor - not stooped & 6 & 35.6 & 67 & 22.9 & \\
\hline Ticagrelor stopped - physician-based decision & 1 & 5.9 & 1 & 14.7 & \\
\hline Ticagrelor stopped - cost & 10 & 58.8 & 178 & 61.0 & \\
\hline Ticagrelor stopped - non-availability of drug & 0 & 0.0 & 3 & 1.0 & \\
\hline Ticagrelor stopped - side effects & 0 & 0.0 & 1 & 0.3 & \\
\hline \multicolumn{6}{|c|}{ Nature of drug that was used during switch-over from ticagrelor } \\
\hline Ticagrelor continued & 6 & 35.3 & 67 & 22.9 & \multirow[t]{3}{*}{0.45} \\
\hline Clopidogrel & 11 & 64.7 & 219 & 75.0 & \\
\hline Prasugrel & 0 & 0.0 & 6 & 2.1 & \\
\hline \multicolumn{6}{|l|}{ Timing of ticagrelor stopped and event } \\
\hline Not stopped & 6 & 35.3 & 66 & 22.6 & \\
\hline Stopped $<1$ month & 2 & 11.8 & 13 & 4.5 & \multirow[t]{5}{*}{0.44} \\
\hline Stopped 1-3 months & 1 & 5.9 & 31 & 10.6 & \\
\hline Stopped 3-6 months & 2 & 11.8 & 29 & 9.9 & \\
\hline Stopped 6-12 months & 3 & 17.6 & 49 & 16.8 & \\
\hline Stopped $>12$ months & 3 & 17.6 & 104 & 35.6 & \\
\hline
\end{tabular}

important factor in the discontinuation of the drug, it was stopped at the discretion of the physician in the majority of patients. Newer oral P2Y12 receptor blockers like ticagrelor and prasugrel have been shown to have increased bleeding risk as compared to clopidogrel [2, 3]. Similar to the PLATO trial, a large prospective registry from Sweden has shown better outcomes with ticagrelor as compared to clopidogrel [4]. Though few case reports from India attributed increased risk of bleeding to newer antiplatelet agents like ticagrelor [5], large observational studies have documented the safety of ticagrelor and prasugrel in the Indian subset of patients [68]. Similar to the other two studies from India, we observed ticagrelor to be safe in Indian patients. Major societal guidelines recommend continuing ticagrelor at least 12 months post-acute coronary syndrome interventions [9-11] based on the PLATO trial. In contrary to the above findings, the CHANGE-DAPT study has shown that ticagrelor was associated with increased events as compared to clopidogrel [12]. They categorized 
the period into the clopidogrel period (2012-2014) and ticagrelor period (2014-2015). They studied more than 2000 patients with ACS. The primary outcome of their study was net adverse cardiac and cerebral events (NACC E) that included all-cause death, any myocardial infarction, stroke, or major bleeding. They found that the 1-year NACCE rate was significantly higher during the ticagrelor period (5.1\% vs. 7.8\%; HR 1.53 [95\% CI 1.08-2.17]; $p=$ 0.02 ) that was attributed to more bleeding in these patients without any benefit in ischemic benefits. Cuisset et al. described the benefit of de-escalation of p2y12 inhibitors [13]. They studied 646 patients and found that switching DAPT strategy after a month of PCI in patients with acute coronary syndrome was superior to an unchanged DAPT strategy without any raise in ischemic events following ACS. In their subgroup analysis related to platelet reactivity study [14], they observed that benefit was seen in all groups irrespective of their platelet reactivity as assessed by vasodilator-stimulated phosphoprotein (VASP) assay. It was also found that greater benefits were seen in patients with lower platelet reactivity. In our study, we found no increased clinical events in patients who were continued on ticagrelor as compared to those who had been switched over to other P2Y12 agents. During swapping to clopidogrel, most of our patients were loaded with $300 \mathrm{mg}$ of clopidogrel. In a recently presented study, it was found that loading with $600 \mathrm{mg}$ of clopidogrel appeared a better strategy than $300 \mathrm{mg}$ loading dosage [15].

In addition to the effect of early discontinuation of ticagrelor, we intended to study the reason behind the same. In the Paris registry, patients who had PCI were studied about the effect of cessation of DAPT, the reason behind the same, and its effect on clinical events [16]. We observed that ticagrelor was stopped in 237 patients $(76.7 \%)$ of patients. They were stopped according to the physician's discretion in $79.3 \%$ of patients, whereas it was the cost of the drug that made the patient to get swapped to other agents in $18.6 \%$. Non-availability of the drug and the side effects were the reason for discontinuation in very few patients only. Clopidogrel was used as the replacement antiplatelet agent in the majority of patients. Ease of availability, long-term safety data, lesser bleeding complications, and cost of clopidogrel might have been the reason for swapping to clopidogrel instead of prasugrel. In one fifth of the patients, the cost of the drug was the reason behind the discontinuation. The availability of generic versions of ticagrelor may change this pattern of practice. We also observed no difference in outcomes of the patients according to the reason for stopping the drug.

\section{Conclusion}

In patients with acute coronary syndrome who undergo PCI, we observed that early discontinuation of ticagrelor and switching over to other P2Y12 inhibitors after discharge did not affect the composite outcome of death, recurrent myocardial infarctions, re-intervention, and major bleeding requiring transfusions. More than $75 \%$, ticagrelor was switched-over to another P2Y12 agent. Switching-over to other drug was performed frequently after 6 months post PCI. Around $80 \%$ of patients, the change was made by their physician. Clopidogrel was the primary replacement agent.

\section{Limitations}

It was a retrospective study. Hence, all possible limitations due to retrospective study hold for this study. Though we arbitrarily categorized the reason for stopping the drug into different categories including the physician's discretion, this might not be perfectly correct due to the retrospective nature of the study. Period of overlap between the groups cannot be excluded absolutely considering retrospective nature of the study. Events that happened in our study were few. That might be the reason for not having any significant difference between the groups. We could not contact 15 patients. It was a single-center experience. Whether it could be generalized to other centers remains a question.

\section{Abbreviations \\ TRITON TIMI-38: Prasugrel versus clopidogrel in patients with acute coronary syndromes; PLATO: Ticagrelor versus clopidogrel in patients with acute coronary syndromes; CHANGE DAPT: Clopidogrel or ticagrelor in acute coronary syndrome patients treated with newer-generation drug-eluting stents}

\section{Acknowledgements}

All patients and patients' advisors who have agreed to participate in this trial. We also thank the Apollo Hospitals, Vanagram, Chennai.

\section{Declarations}

For the purposes of submission, please see below:

1) None of the paper's contents have been previously published;

2) All authors have read and approved the manuscript;

3) There is an agreement to be accountable for all aspects of the work in ensuring that questions related to the accuracy or integrity of any part of the work are appropriately investigated and resolved;

4) There is full disclosure of any relationship with industry or no such relationship exists

\section{Authors' contributions}

NBS: Conceptualization, designing, interpretation supervision, writing the original draft, review, and editing. RS-Interpretation, review, and editing. YRAcquisition, analysis, review, and editing. DT-Acquisition, analysis, review, and editing. $\mathrm{AM}^{-}$Acquisition, analysis, review, and editing. $\mathrm{DM}^{-}$Acquisition, analysis, review, and editing. DK- Acquisition, analysis, Review \& Editing. MJKFormal analysis and software. SKS-Acquisition, analysis, review, and editing. AS-Acquisition, analysis, review, and editing. PKJ-Acquisition, analysis, review, and editing. HP-Acquisition, analysis, review, and editing. AL-Acquisition, analysis, review, and editing. AG-Acquisition, analysis, review, and editing. KNRInterpretation, review, and editing. KAA-Interpretation, guarantor, review, and editing. In addition, all authors have approved the submitted version and have agreed both to be personally accountable for the author's own contributions and to ensure that questions related to the accuracy or integrity of any part of the work, even ones in which the author was not personally involved, are appropriately investigated, resolved, and the resolution documented in the literature. 
Funding

None.

Availability of data and materials

If required, we can submit the data sheet.

Ethics approval and consent to participate

Institute's Ethics committee clearance was obtained; IEC-Clincal studies; Apollo hospitals, Chennai; IEC-AVH-002/10-16. Written informed consent to participate was obtained from all participants.

\section{Consent for publication}

Not applicable.

\section{Competing interests}

The authors declare that they have no competing interests.

\section{Author details}

'Department of Cardiology, Sri Ramachandra Institute of Higher Education and Research, Chennai, Tamil Nadu, India. ${ }^{2}$ Adjunct Faculty-Indian Institute of Technology Madras, Chennai, Tamil Nadu, India. ${ }^{3}$ Department of Cardiology, Apollo Specialty Hospitals, Chennai, Tamil Nadu, India. ${ }^{4}$ Department of Cardiology, Jaswant Rai Specialty Hospitals, Chennai, Tamil Nadu, India. ${ }^{5}$ National Health Mission, Chennai, Tamil Nadu, India.

Received: 24 October 2020 Accepted: 16 December 2020

Published online: 11 January 2021

\section{References}

1. Krishnan MN, Zachariah G, Venugopal K, Mohanan PP, Harikrishnan S, Sanjay $\mathrm{G}$ et al (2016) Prevalence of coronary artery disease and its risk factors in Kerala, South India: a community-based cross-sectional study. BMC Cardiovasc Disord 16:12

2. Wallentin L, Becker RC, Budaj A, Cannon CP, Emanuelsson H, Held C et al (2009) Ticagrelor versus clopidogrel in patients with acute coronary syndromes. N Engl J Med 361(11):1045-1057

3. Wiviott SD, Braunwald E, CH MC, Montalescot G, Ruzyllo W, Gottlieb S et al (2007) Prasugrel versus clopidogrel in patients with acute coronary syndromes. N Engl J Med 357(20):2001-2015

4. Sahlén A, Varenhorst $C$, Lagerqvist B, Renlund $H$, Omerovic E, Erlinge D et al (2016) Outcomes in patients treated with ticagrelor or clopidogrel after acute myocardial infarction: experiences from SWEDEHEART registry. Eur Heart J 37(44):3335-3342

5. Suryanarayana Sharma PM, Tekkatte Jagannatha A, Javali M, Hegde AV, Mahale R, Null M et al (2015) Spontaneous subdural hematoma and antiplatelet therapy: does the efficacy of Ticagrelor come with added risk? Indian Heart J 67(Suppl 3):S30-S35

6. Kaul U, Sethi A, Arambam P, Omar AK, Keshava R, Roy S et al (2014) Safety of Prasugrel in Indian patients - multicentric registry of 1000 cases. Indian Heart J 66(6):598-601

7. Dalal JJ, Digrajkar A, Gandhi A (2016) Oral antiplatelet therapy and platelet inhibition: an experience from a tertiary care center. Indian Heart J 68(5): 624-631

8. Kumar V, Kumari K, Talwar KK, Prasad D, Agarwal S et al (2018) Clinical safety profile of ticagrelor compared to clopidogrel in 1208 patients: real-world evidence. Egypt Heart J EHJ Off Bull Egypt Soc Cardiol 70(4):375-378

9. Levine GN, Bates ER, Bittl JA, Brindis RG, Fihn SD, Fleisher LA et al (2016) 2016 ACC/AHA guideline focused update on duration of dual antiplatelet therapy in patients with coronary artery disease: a report of the American College of Cardiology/American Heart Association Task Force on Clinical Practice Guidelines: An Update of the 2011 ACCF/AHA/SCAI Guideline for Percutaneous Coronary Intervention, 2011 ACCF/AHA Guideline for Coronary Artery Bypass Graft Surgery, 2012 ACC/AHA/ACP/AATS/PCNA/ SCAI/STS Guideline for the Diagnosis and Management of Patients With Stable Ischemic Heart Disease, 2013 ACCF/AHA Guideline for the Management of ST-Elevation Myocardial Infarction, 2014 AHA/ACC Guideline for the Management of Patients With Non-ST-Elevation Acute Coronary Syndromes, and 2014 ACC/AHA Guideline on Perioperative Cardiovascular Evaluation and Management of Patients Undergoing Noncardiac Surgery. Circulation 134(10):e123-e155
10. Ibanez B, James S, Agewall S, Antunes MJ, Bucciarelli-Ducci C, Bueno H et al (2018) 2017 ESC Guidelines for the management of acute myocardial infarction in patients presenting with ST-segment elevation: the task force for the management of acute myocardial infarction in patients presenting with ST-segment elevation of the European Society of Cardiology (ESC). Eur Heart J 39(2):119-177

11. Roffi M, Patrono C, Collet J-P, Mueller C, Valgimigli M, Andreotti F et al (2016) 2015 ESC Guidelines for the management of acute coronary syndromes in patients presenting without persistent ST-segment elevation: task force for the management of acute coronary syndromes in patients presenting without persistent ST-segment elevation of the European Society of Cardiology (ESC). Eur Heart J 37(3):267-315

12. Zocca P, van der Heijden LC, Kok MM, Löwik MM, Hartmann M, Stoel MG et al (2017) Clopidogrel or ticagrelor in acute coronary syndrome patients treated with newer-generation drug-eluting stents: CHANGE DAPT. Eurolntervention J Eur Collab Work Group Interv Cardiol Eur Soc Cardiol 13(10):1168-1176

13. Cuisset T, Deharo P, Quilici J, Johnson TW, Deffarges S, Bassez C et al (2017) Benefit of switching dual antiplatelet therapy after acute coronary syndrome: the TOPIC (timing of platelet inhibition after acute coronary syndrome) randomized study. Eur Heart J 38(41):3070-3078

14. Deharo P, Quilici J, Camoin-Jau L, Johnson TW, Bassez C, Bonnet G et al (2017) Benefit of switching dual antiplatelet therapy after acute coronary syndrome according to on-treatment platelet reactivity: the TOPIC-VASP pre-specified analysis of the TOPIC randomized study. JACC CardiovasC Interv 10(24):2560-2570

15. Angiolillo DJ, Rollini F, Storey RF, Bhatt DL, James S, Schneider DJ et al (2017) International expert consensus on switching platelet P2Y12 receptorinhibiting therapies. Circulation 136(20):1955-1975

16. Mehran R, Baber U, Steg PG, Ariti C, Weisz G, Witzenbichler B, et al. Cessation of dual antiplatelet treatment and cardiac events after percutaneous coronary intervention (PARIS): 2 year results from a prospective observational study. Lancet. 2013;382(9906):1714-1722. https:// doi.org/10.1016/S0140-6736(13)61720-1. Epub 2013 Sep 1.

\section{Publisher's Note}

Springer Nature remains neutral with regard to jurisdictional claims in published maps and institutional affiliations.

\section{Submit your manuscript to a SpringerOpen ${ }^{\circ}$ journal and benefit from:}

- Convenient online submission

- Rigorous peer review

- Open access: articles freely available online

- High visibility within the field

- Retaining the copyright to your article

Submit your next manuscript at $>$ springeropen.com 